\title{
Design and Implementation of a Novel Microstrip Filter
}

\author{
G.T.Bharathy, S.Bhavanisankari, T.Tamilselvi, G.Bhargavi
}

\begin{abstract}
Microwave filters are circuits which perform signal processing functions, particularly to eliminate unwanted frequency components from the signal, to enhance wanted ones, or both. Electronic filters can be passive or active(depends on components used) Analog or digital(depends on input signal) High-pass, Low-pass, Band-pass, Band-stop or all other pass (depends on frequency) Infinite impulse response (IIR type) or Finite impulse response (FIR type) (Depends on response) Microstrip is a type of electrical transmission line which can be fabricated using printed circuit board technology, and is used to convey microwave frequency signals. Microwave components such as antennas, couplers, filters, power dividers etc can be formed using microstrip line. This paper aims on filter design, using microstrip transmission line, with a Non-Periodic technique especially using Defected Microstrip Structure to be operated in the $C$ - Band frequency.
\end{abstract}

Index Terms: Microstrip Filter, Defected Microstrip Structure, T - Shaped structure.

\section{INTRODUCTION}

Many communication system has RF system which performs signal processing using RF Microstrip filter due to its low cost. The transmitters and receivers are generally operated in $800 \mathrm{MHz}$ to $30 \mathrm{GHz}$. This paper concentrates on the filter which passes frequency of $4 \mathrm{GHz}$ to $8 \mathrm{GHz}(\mathrm{C}$ Band). Periodic and Non-Periodic microstrip line perturbation techniques are the two common techniques used in designing microstrip RF filter. Multiband Matched Band stop Filter, Dual-mode Ring Resonator, distorted UC-PGB (Uniplanar Compact photonic Band gap), high impedance surface Electromagnetic Bandgap, Ground Plane Aperture, Photonic Bandgap (PBG), Defected Ground Structure (DGS), Defected Microstrip Structure (DMS) are the RF Microstrip designs designed using the above two techniques. This paper elaborates on Non-Periodic technique especially using Defected Microstrip Structure. The drawback of Defected Ground Structure is leakage through ground plane, radiation through etched slot and distortion are overcome by Defected Microstrip Structure. By using DMS line properties there is effective increase in inductance and capacitance which gives stopband characteristics. The microstrip line can be realized in Defected Microstrip Structure by etching the slot. It improves the microwave circuit performance. Based on the structure the Defected Microstrip Structure can be shaped in T,G,L and spiral. This paper focuses on designing a microstrip filter in T-Shape.

\section{BANDSTOP FILTER}

The basic arrangement of the optimal Bandstop filter depends on the open circuited transmission line stub network.

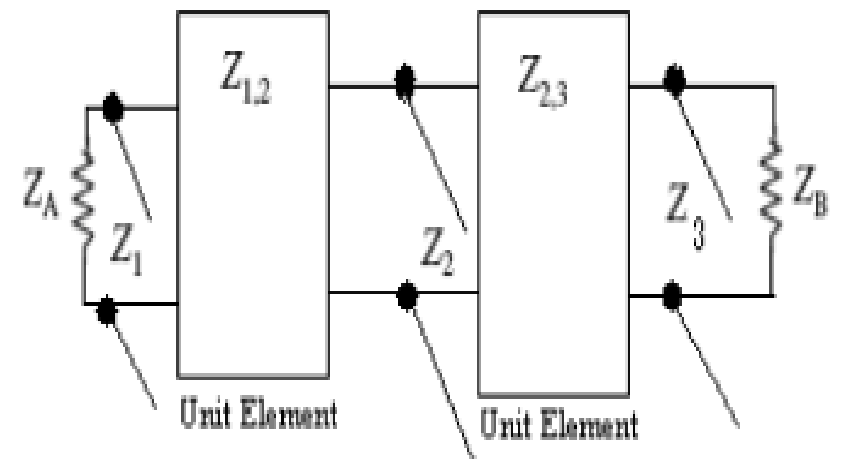

Fig.1 Transmission line representation of BSF

\section{DEFECTED MICROSTRIP STRUCTURE}

Periodic structures commonly display passband and stopband description in a variety of bands of wave number determined by the nature of the structure. Defected microstrip structure (DMS) is constructed by etching distinct slot patterns in the microstrip line, and it exhibits the properties of slow-wave, eliminating microwaves in certain frequencies that are analogous to the defected ground structure (DGS) but without any management of the ground plane. DMS is effortlessly incorporated with other microwave circuits, and it has an efficiently reduced circuit size in relation to DGS. DMS Increase in the electric length of the microstrip line DMS, makes the effective capacitance and inductance to increase. Resonances are created due to the defection in the microstrip line. Several novel, compact microwave components and antennas can be constructed with the help of the advantages and characteristics of DMS.

Microwave discontinuity like gap, T-shape, bend, step and etc. are some common elements that are used to form a microwave structures which leads to specific design performances.

G.T.Bharathy, Electronics and Communication Engineering, Jerusalem College of Engineering, Chennai, India.

S.Bhavanisankari, Electronics and Communication Engineering, Jerusalem College of Engineering, Chennai, India.

T.Tamilselvi, Electronics and Communication Engineering, Jerusalem College of Engineering, Chennai, India.

G.Bhargavi, Electronics and Communication Engineering, Jerusalem College of Engineering, Chennai, India.

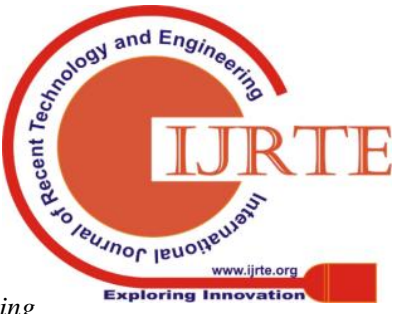




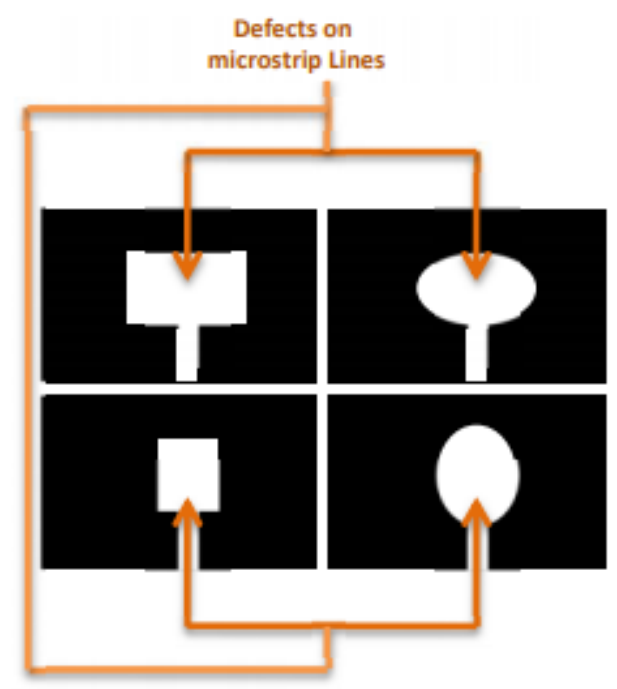

Fig.2. Defected Microstrip Structure

\section{MICROSTRIP FILTERS}

Relationship between the desired frequency characteristics and the parameters of the filter structure is required to construct specific filters. The distributed parameters can be related to the corresponding parameters of lumped element prototypes. Richard's Transformation and Kuroda's Identities ( $\lambda / 8$ Lines), are most commonly used for which $\mathrm{X}=\mathrm{jZo}$. Richard's idea is to use variable Zo (width of microstrip). Finally the filter design has to be scaled to the desired $\lambda \mathrm{c}$

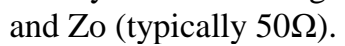

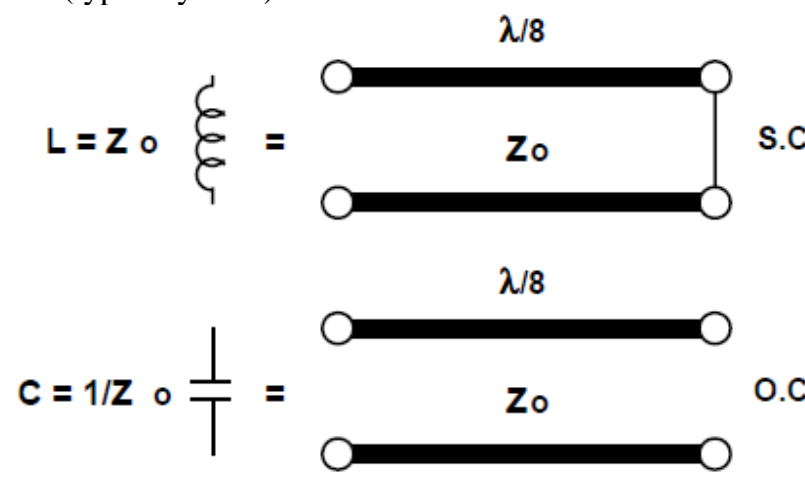

Fig.3 Lumped Elements and its Equivalent Distributed Line.

Kuroda's idea is use the $\lambda / 8$ line of appropriate Zo to transform awkward or unrealizable elements to those with more tractable values and geometry. The series inductive stub in the diagram here can be replaced by a shunt capacitive stub on the other end of the $\lambda / 8$ line, with different values of characteristic impedance determined by

$\mathrm{k}=\mathrm{n} 2=1+Z 1 / Z 2$

consider a prototype network with the values

$\mathrm{L}=\mathrm{Z} 1=0.5$ and $\mathrm{Z} 2=1$

$\mathrm{k}=\mathrm{n} 2=1+Z 1 / Z 2=1.5$

The equivalent network has, the series transmission line element with $\mathrm{Z}=1.5 \mathrm{Z} 1=0.75$

and the shunt capacitive stub has $Z=1.5 Z 2=1.5$. Kuroda's four identities are a resources using which the series stubs that arise from series $\mathrm{L}$ or $\mathrm{C}$ are eliminated in the prototype networks

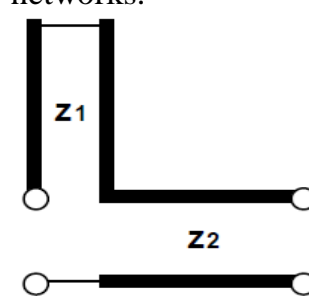

$=$

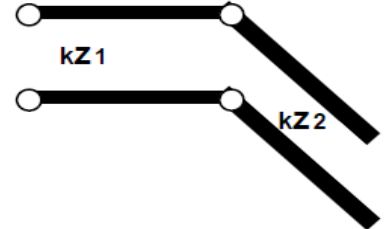

Fig.4 Prototype Network With an Inductor

The filter is designed by the following steps:

- Lumped element low pass prototype

- The series inductors are converted to series stubs, and the shunt capacitors is converted to shunt stubs

- $\lambda / 8$ lines with $\mathrm{Zo}=1$ are added at input and output

- Obtain the physical dimensions by transforming the design to $50 \Omega$.

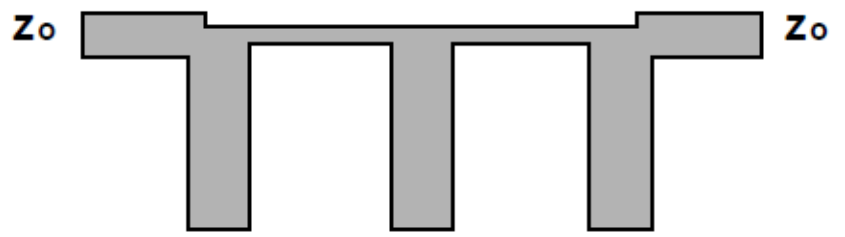

Fig.5 Microstrip Structure

\section{DESIGN SPECIFICATIONS}

The filter is simulated with start frequency of $4 \mathrm{GHz}$ and stop frequency of $8 \mathrm{GHz}$ with step $0.01 \mathrm{GHz}$. For designing microstrip filter.

The substrate specifications are:

$\mathrm{H}$ (Height of the substrate $)=31 \mathrm{mil}$

$\varepsilon r($ Relative Permitivity $)=2.33$

$\mathrm{T}$ (Conductor thickness $)=17 \mathrm{um}$

TanD $($ Dielectric loss Tangent $)=0.005$

Variable and equation block specifications:

$\mathrm{w} 50=2.31 \mathrm{~mm}$

$\mathrm{w} 54=2.00 \mathrm{~mm}$

$\mathrm{w} 81=1.00 \mathrm{~mm}$

$\mathrm{w} 129=0.32 \mathrm{~mm}$

Microstrip line specifications:

$\mathrm{W}($ Width $)=\mathrm{w} 50$

$\mathrm{L}$ (Length) $=2.5 \mathrm{~mm}$

Microstrip Tee junction specifications:

\begin{tabular}{|c|c|c|}
\hline M TEE 1: & M TEE 2: & M TEE 3: \\
\hline $\mathrm{W} 1=\mathrm{w} 50$ & $\mathrm{~W} 1=\mathrm{w} 129$ & $\mathrm{~W} 1=\mathrm{w} 129$ \\
\hline $\mathrm{W} 2=\mathrm{w} 129$ & $\mathrm{~W} 2=\mathrm{w} 129$ & $\mathrm{~W} 2=\mathrm{w} 50$ \\
\hline W3=w81 & W3=w54 & $\mathrm{W} 3=\mathrm{w} 81$ \\
\hline
\end{tabular}


Microstrip open circuit stub:

MLOC 1,3:

MLOC 2:

$\mathrm{W}=\mathrm{w} 81$

$\mathrm{W}=\mathrm{w} 54$

$\mathrm{L}=4.55 \mathrm{~mm}$

$\mathrm{L}=4.45 \mathrm{~mm}$

\section{SIMULATION RESULTS}
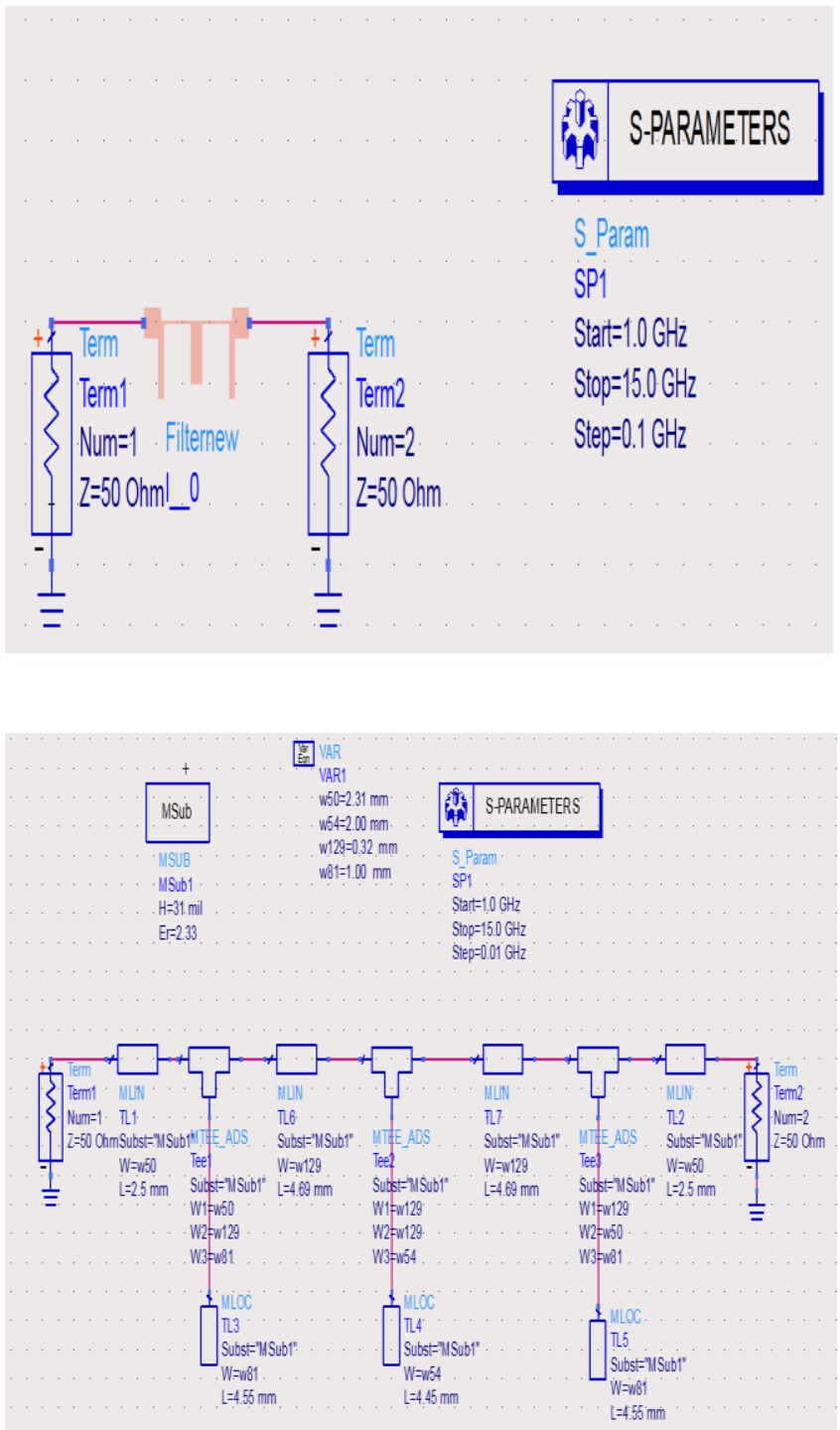

Fig. 6 ADS Schematic Model of the Filter

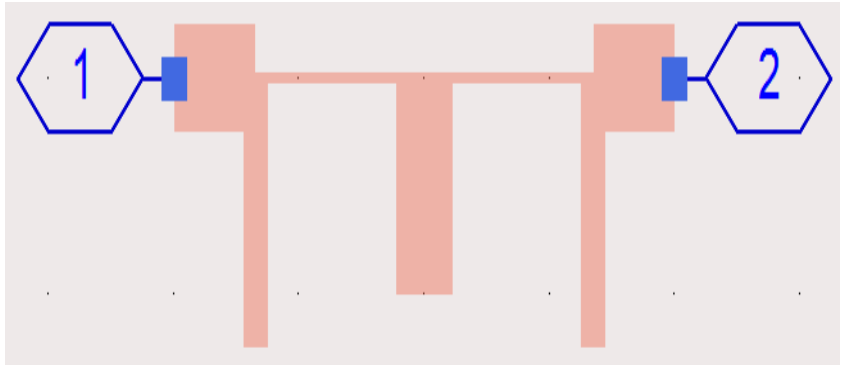

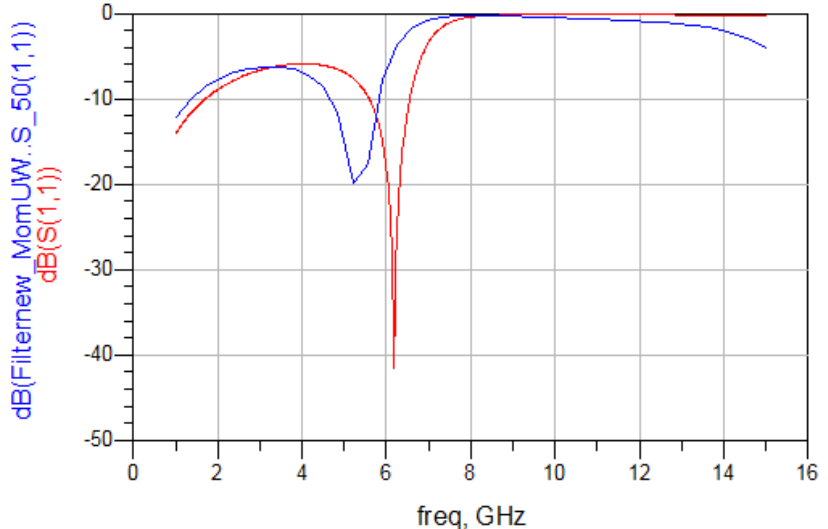

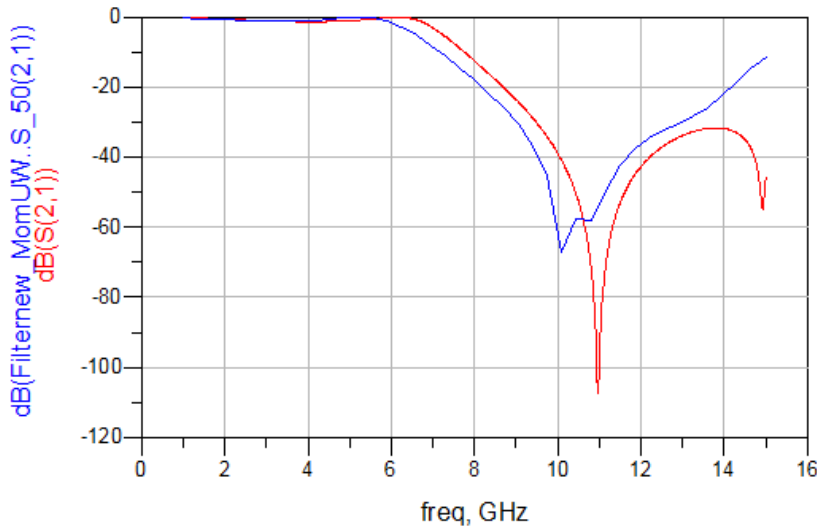

Fig.7 S Parameter Simulation

\section{EM Layout}

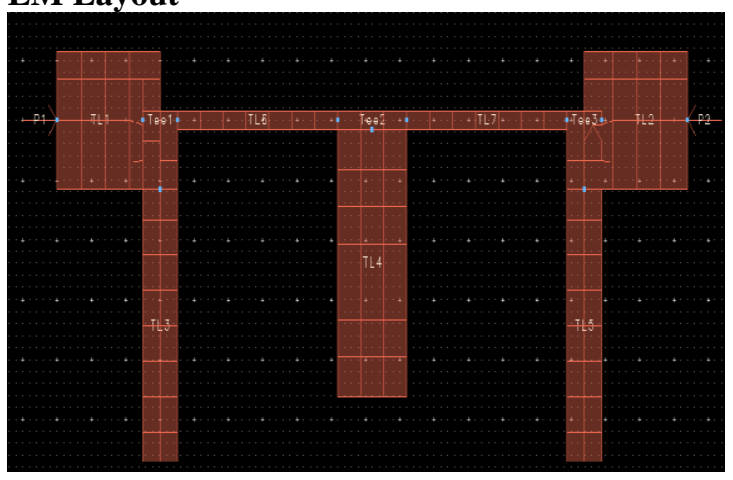

Fig. 8 ADS EM Layout of the Filter

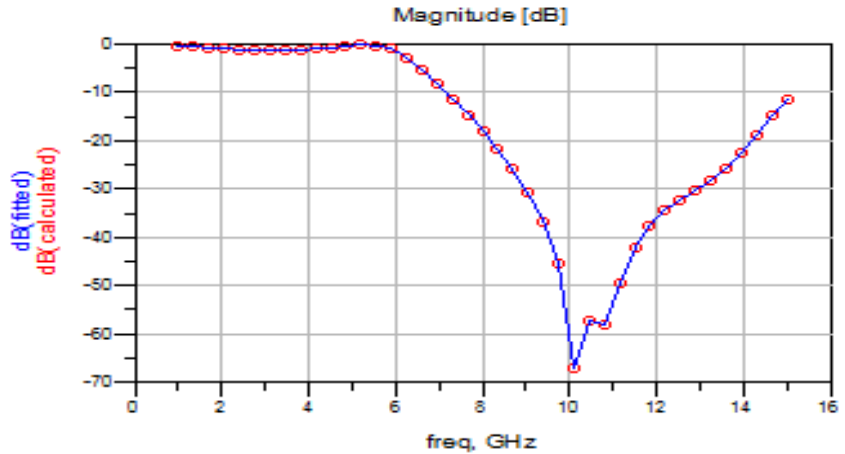

Fig. 9 Magnitude Plot of the S parameters 


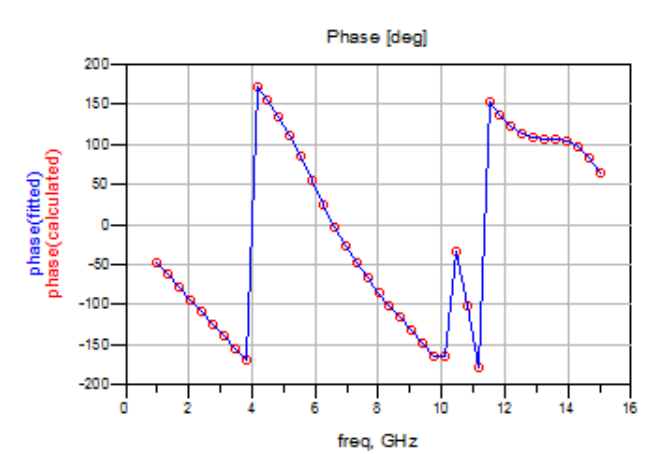

Fig. 10 Phase Plot of the S parameters

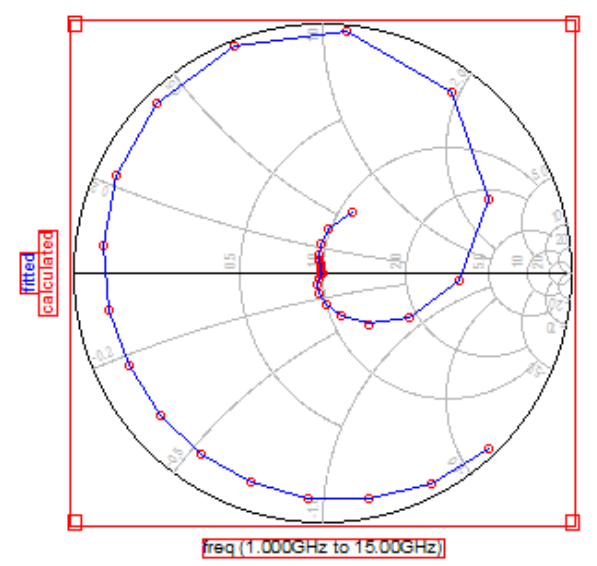

Fig. 11 Polar Plot of the S parameters

The simulations are carried out using ADS software. The schematic model and the EM Layout results shows that the designed microstrip filter works perfectly in the desired C band frequency.

\section{CONCLUSION}

A microstrip configuration is introduced to realize relatively wide bandstop filters. The reliable design process, beside the filter's low profile, weight, and manufacturing cost, makes this filter a good candidate for stopband in C - Band applications. Concurrence between measured and simulated results explains the toughness and dependability of the design method.

\section{REFERENCES}

1. J.A.G. Malherbe, Microwave Transmission Line Filters, Norwood, Artech House Inc, 1979.

2. F.C. Chen, N.Y. Zhang, P.S. Zhang, and Q.X. Chu, "Design of ultrawideb and bandstop filter using defected ground structure," IET Electron. Lett., vol. 49, no. 16, pp. 1010-1011, Aug. 2013.

3. S. Amari, U. Rosenberg, and R. Wu, "In-line pseudoelliptic band-reject filters with nonresonating nodes and/or phase shifts," IEEE Trans. Microw. Theory Tech., vol. 54, no. 1, pp. 428-436, Jan. 2006.

4. M. Mandal, K. Divyabramham, and V.K. Velidi, "Compact wideband bandstop filter with five transmission zeros," IEEE Microw. Wireless Compon. Lett., vol. 22, no. 1, pp. 4-6, Jan. 2012.

5. R.J. Cameron, M. Yu, and Y. Wang, "Direct-coupled microwave filters with single and dual stopbands," IEEE Trans. Microw. Theory Tech., vol. 53, no. 11, pp. 3288-3297, Nov. 2005.

6. M.Y. Hsieh and S.M. Wang, "Compact and wideband microstrip bandstop filter," IEEE Microw. Wireless Compon.Lett., vol. 15, no. 7, pp. 472-474, July 2005.

7. H. Shaman and J.S. Hong, "Wideband bandstop filter with cross coupling," IEEE Trans. Microw. Theory Tech., vol. 55, no.8, pp. 17801785, Aug. 2007.
8. M.K. Mandal, K. Divyabramham, and S. Sanyal, "Compact, wideband bandstop filters with sharp rejection characteristic," IEEE Microw Wireless Component. Lett., vol. 18, no. 10, pp. 665-667, Oct. 2008.

9. M.Á. Sánchez-Soriano, G. Torregrosa-Penalva, and E. Bronchalo, "Compact wideband bandstop filter with four transmission zeros," IEEE Microw. Wireless Compon. Lett., vol. 20, no. 6, pp. 313-315, June 2010. 10. K. Divyabramham, M. Mandal, and S. Sanyal, "Sharp-rejection wideband bandstop filters," IEEE Microw. Wireless Compon. Lett., vol. 18, no. 10 , pp. $662-664$, Oct. 2008.

\section{AUTHORS PROFILE}

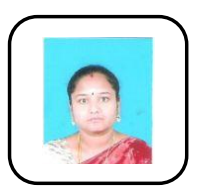

Ms.G.T.Bharathy was born in India in the year 1979 . She completed B.E degree in Electronics and Communication Engineering from Easwari Engineering College, Chennai, Madras University, India in the year 2000 and M.E degree in Communication Systems from Shri Venkateshwara College of Engineering, Chennai, Anna University, India in the year 2005. She is now working as Senior Assistant Professor in Jerusalem College of Engineering, Dept. of Electronics and Communication Engineering, Chennai. She is a life member in ISTE. She has worked as Lecturer in the department of ECE in Anand Institute of Higher Technology and Prince Shri Venkateshwara Padmavathi College of Engineering, Chennai. Her research interest is RF and microwave circuits and systems.

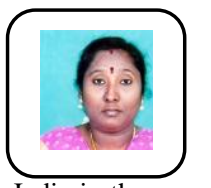

Ms.S.Bhavani Sankari was born in India in the year 1978. She completed B.E degree in Electronics and Communication Engineering from Thanthai Periyar Government College of Engineering, Madras University, India in the year 1995 and M.E degree in Industrial Electronics from Sri Jeyachamarajendra College of Engineering, Visveswaraya University, India in the year 2003. She is now working as an Associate Professor in Jerusalem College of Engineering, Dept. of Electronics and Communication Engineering, Chennai. She is a life member in ISTE. Her research interest is Communication, Signal Processing.

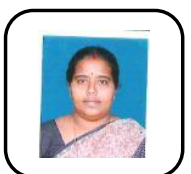

Ms.T.Tamilselvi was born in India in the year 1978. She completed B.E degree in Electronics and Communication Engineering from Adhiparasakthi Engineering College, Madras University, India in the year 2000 and M.E degree in Embedded System Technologies from College of Engineering, Guindy (CEG Main Campus), Anna University, India in the year 2006. She is now working as Senior Assistant Professor in Jerusalem College of Engineering, Dept. of Electronics and Communication Engineering, Chennai. She is a life member in ISTE. Her research interest is VLSI and Embedded design.

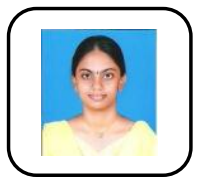

Ms.G.Bhargavi was born in India in the year 1987. She completed B.E degree in Electronics and Communication Engineering from Sri Muthukumaran Institute of Technology, Anna University, India in the year 2009 and M.E degree in Communication Systems from Shri Venkateshwara College of Engineering, Chennai, Anna University, India in the year 2011. She is now working as Assistant Professor in Jerusalem College of Engineering, Dept. of Electronics and Communication Engineering, Chennai. She is a life member in ISTE. Her research interest is Communication Systems.

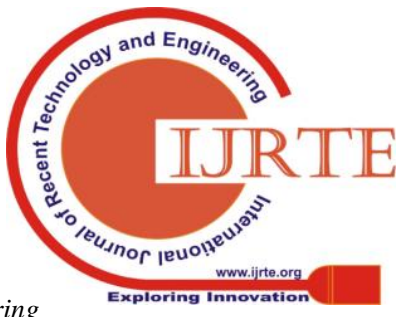

